\title{
Thick-wall cavity predicts worse progression-free survival in lung adenocarcinoma treated with first-line EGFR-TKIs
}

Fei Zhou ${ }^{1+}\left(\mathbb{D}\right.$, Wanrong Ma ${ }^{2+}$, Wei $\mathrm{Li}^{1+}$, Huijuan Ni ${ }^{1}$, Guanghui Gao ${ }^{1}$, Xiaoxia Chen ${ }^{1 *}$, Jie Zhang ${ }^{1 *}$ and Jingyun Shi ${ }^{3^{*}}$

\begin{abstract}
Background: Cavity occurs in 5.7 to $14.9 \%$ of patients with lung adenocarcinoma (ADC). However, the impact of cavity on the therapeutic response to epidermal growth factor receptor-tyrosine kinase inhibitors (EGFR-TKIs) in ADC patients with EGFR mutations remains unclear. The aim of the present retrospective study was to elucidate the incidence and detailed characteristics of EGFR-mutant cavitary ADC and investigate the efficacy of EGFR-TKI treatment in this subgroup.
\end{abstract}

Methods: Two hundred seventy-six consecutive patients with advanced EGFR-mutant lung ADC treated with first-line EGFR-TKIs were enrolled. Cavitation and the thickness of cavity wall were assessed based on highresolution computed tomography scans. Progression-free survival (PFS) was analyzed by the Kaplan-Meier plots and the log-rank test was used to calculate the significance between groups.

Results: Cavity occurred in 5.4\% (15/276) of patients with EGFR-mutant lung ADC and was more prevalent among male patients (66.7\% vs. 33.3\%, $P=0.008)$. Of the 15 EGFR-mutant cavitary ADC, 9 patients had exon 19 deletion (19DEL) and 6 harbored L858R mutation, 9 patients had thick-wall cavity while 6 had thin-wall cavity. Cavity had an adverse impact on the PFS of EGFR-mutant ADC treated with first-line EGFR-TKIs (noncavity versus cavity, 11.0 versus 6.5 months, hazard ratio [HR]: 0.33, 95\% confidence interval [CI], $0.15-0.73, P=0.003$ ). The impaired effect was only observed in patients with L858R mutation (11.0 vs. 4.2 months, $\mathrm{HR}: 0.05,95 \% \mathrm{Cl}, 0.01-0.27, P=0.0003$ ) but not in those with 19DEL (10.4 versus 9.7 months, HR: 0.73 , 95\%Cl, 0.30-1.75, $P=0.483$ ). All six L858R-mutant cavitary ADC patients had thick-wall cavity while thick-wall cavity was only identified in one thirds (3/9) of patients with 19DEL. Further analyses showed that patients with thick-wall cavity had worse PFS (6.0 versus 11.0 months, $P=0.013$ ). Multivariate analysis identified cavity as an independent predictive factor for PFS (HR: 0.49, 95\% Cl, 0.26-0.90, $P=0.022$ ).

Conclusion: Cavitary ADC was associated with a worse PFS of first-line EGFR-TKI therapy, mainly in those with L858R mutation. Thick-wall cavity formation may be the main cause that contribute to the worse PFS.

Keywords: Cavitation, Adenocarcinoma, EGFR-TKl, Hypoxia

\footnotetext{
*Correspondence: cheetos_xx@126.com; zhangjie2172@163.com; shijingyun89179@126.com

${ }^{\dagger}$ Fei Zhou, Wanrong Ma and Wei Li contributed equally to this work.

'Department of Oncology, Shanghai Pulmonary Hospital, Tongji University School of Medicine, No 507 Zhengmin Road, Yangpu District, Shanghai, China

${ }^{3}$ Department of Imaging, Shanghai Pulmonary Hospital, Tongji University School of Medicine, No 507 Zhengmin Road, Yangpu District, Shanghai 200433, China

Full list of author information is available at the end of the article
}

(c) The Author(s). 2018 Open Access This article is distributed under the terms of the Creative Commons Attribution 4.0 International License (http://creativecommons.org/licenses/by/4.0/), which permits unrestricted use, distribution, and reproduction in any medium, provided you give appropriate credit to the original author(s) and the source, provide a link to the Creative Commons license, and indicate if changes were made. The Creative Commons Public Domain Dedication waiver (http://creativecommons.org/publicdomain/zero/1.0/) applies to the data made available in this article, unless otherwise stated. 


\section{Background}

Epidermal growth factor receptor (EGFR) sensitizing mutations occur in about $40-78 \%$ of Asian patients with lung adenocarcinoma (ADC) [1-4]. For patients with EGFR sensitizing mutations, EGFR-tyrosine kinase inhibitors (EGFR-TKIs) have resulted in a significant improvement in progression-free survival (PFS), objective response rate (ORR), and quality of life (QoL) when compared with classical platinum-based chemotherapy [5-8]. However, even in EGFR-mutant patients, 10-30\% may not benefit from initial EGFR-TKI treatment and even experience rapid disease progression [5-8].

Cavitation in a tumor nodule is previously thought to be more prevalent in patients with squamous cell carcinoma $[9,10]$. As the prevalence of lung ADC increases, cavitary ADC has also been reported, with an incidence of 5.7 to $14.9 \%$ in patients with lung ADC [11-14]. Compared with noncavitary ADC, cavitary ADC is associated with a worse prognosis [14]. Previous study has demonstrated that inadequate vascularization might account for cavity formation and cavitary ADC has a higher frequency of vascular invasion than noncavitary ADC [14]. Therefore, the occlusion of feeding vessels by vascular invasion in cavitary ADC could create a hypoxia microenvironment. As hypoxia could induce resistance to EGFR-TKIs in EGFR-mutant lung cancer $[15,16]$, we speculate cavity formation may impair the therapeutic response to EGFR-TKIs in EGFR-mutant ADC patients.

The aim of the present retrospective study was to elucidate the incidence and detailed characteristics of EGFR-mutant cavitary ADC and investigate the efficacy of EGFR-TKI treatment in this subgroup.

\section{Methods}

\section{Patient selection}

Consecutive patients with advanced EGFR-mutant lung ADC treated with first-line EGFR-TKIs at the Department of Oncology, Shanghai Pulmonary Hospital, China from November 2011 to January 2016 were enrolled. The lung ADC diagnosis was diagnosed pathologically according to World Health Organization (WHO) pathology classification [17]. All clinicopathologic data were extracted from electronic medical record in Shanghai Pulmonary Hospital. EGFR common mutations were defined as mutations including exon 19 deletion (19DEL) and Leu858Arg point mutation in exon 21 (L858R). EGFR rare mutations were those mutations in exons 18 and 20, other than 19DEL and L858R mutations.

The study protocol was approved by the Ethics Committee of Shanghai Pulmonary Hospital. The written informed consent was obtained from each participant to use the clinical data for research before any medical interventions.
Review of computed tomography images

Computed tomography (CT) scans were performed for all patients via two CT machines (Brilliance, Philips Medical Systems Inc., Cleveland, the US $[64 \times 1 \mathrm{~mm}$ acquisition; slice width $1 \mathrm{~mm}$ ] or SOMATOM Definition AS, Siemens Aktiengesell-schaft, Munich, Germany [128 $\times 1 \mathrm{~mm}$ acquisition; slice width $1 \mathrm{~mm}]$ ) before bronchoscopy or a percutaneous CT-guided biopsy.

The CT images were evaluated by two investigators (FZ and WL) for tumor cavitation, independently. Tumor cavitation was defined as the presence of an air-containing space with a diameter of greater than $5 \mathrm{~mm}$ within the primary tumor and which was not identifiable as an airway, as previous described [14, 18]. Disagreements were resolved by consensus or a third reviewer (JZ or JS).

The thickness of cavity wall was measurable at intervals of $1 \mathrm{~mm}$, which was determined based on the thickest segment of the cavity wall totally orthogonal to the image plane. According to previous study [18], a cavity wall thickness of greater than $4 \mathrm{~mm}$ was defined as thick-wall cavity while a cavity wall thickness $4 \mathrm{~mm}$ or less was defined as thin-wall cavity. The dynamic volume perfusion CT (dVPCT) was used to quantitatively assess tumor permeability, blood flow (BF), blood volume (BV) and mean transit time (MTT). The detailed procedures of dVPCT were described in our previous studies [19, 20].

\section{Molecular analyses}

All mutational analyses were performed at the Department of Lung Cancer and Immunology, Shanghai Pulmonary Hospital. Briefly, DNA from tumor tissue was extracted using the DNeasy Blood and Tissue Kit or the QIAamp DNA FFPE Tissue Kit (both from Qiagen, Hilden, Germany). EGFR mutations (exons 18-21) were detected by amplification refractory mutation system (ARMS) (Amoy Diagnostics Co. Ltd., Xiamen, China). At the time of development of acquired resistance, re-biopsy samples were obtained from either primary sites or metastasis sites for further analysis to identify potential mechanisms. Detailed procedures were described in our previous studies [21-24].

\section{Statistical analysis}

Categorical variables were compared using Fisher's exact test or Chi-square test, and continuous variables were compared using the Mann-Whitney U test. PFS was defined as the time from treatment commencement of EGFR-TKI to confirmed disease progression or death of any cause. PFS was analyzed by the Kaplan-Meier plots and the log-rank test was used to calculate the significance between groups. The predictive factors for PFS were analyzed using univariate and multivariate COX proportional hazard model. The two-sided significance 
Table 1 Patient Characteristics in Cavitary and Noncavitary Adenocarcinoma with EGFR mutations

\begin{tabular}{|c|c|c|c|c|}
\hline Characteristic & $\begin{array}{l}\text { All patients } \\
N=276\end{array}$ & $\begin{array}{l}\text { Cavity } \\
N=15\end{array}$ & $\begin{array}{l}\text { Noncavity } \\
N=261\end{array}$ & $P$ \\
\hline Age, Median (range), y & $61(26-86)$ & $61(37-76)$ & $61(26-86)$ & 0.271 \\
\hline$\leq 65$ & $178(64.5)$ & $12(80.0)$ & $166(63.6)$ & \\
\hline$>65$ & $98(35.5)$ & $3(20.0)$ & $95(36.4)$ & \\
\hline Gender, no. (\%) & & & & 0.008 \\
\hline Male & $96(34.8)$ & $10(66.7)$ & $86(33.0)$ & \\
\hline Female & $108(65.2)$ & $5(33.3)$ & $175(67.0)$ & \\
\hline Smoking history, no. (\%) & & & & 0.494 \\
\hline Nonsmokers & $224(81.2)$ & $11(73.3)$ & $213(81.6)$ & \\
\hline Former or current smokers & $52(18.8)$ & $4(26.7)$ & $48(18.4)$ & \\
\hline ECOG PS, no. (\%) & & & & $0.377^{a}$ \\
\hline 0 & $10(3.6)$ & $1(6.7)$ & $9(3.4)$ & \\
\hline 1 & $242(87.7)$ & $14(93.3)$ & $228(87.4)$ & \\
\hline 2 & $20(7.2)$ & $0(0.0)$ & $20(7.7)$ & \\
\hline 3 & $4(1.4)$ & $0(0.0)$ & $4(1.5)$ & \\
\hline TNM stage, no. (\%) & & & & $0.478^{b}$ \\
\hline Recurrent & $14(5.1)$ & $1(6.7)$ & $13(5.0)$ & \\
\hline$\||| B$ & $31(11.2)$ & $0(0.0)$ & $31(11.9)$ & \\
\hline IV & $231(83.7)$ & $14(93.3)$ & $217(83.1)$ & \\
\hline T stage, no. (\%) & & & & 0.270 \\
\hline $\mathrm{T} 1-2$ & $101(36.6)$ & $5(33.3)$ & $96(36.8)$ & \\
\hline Т3-4 & $175(63.4)$ & $10(66.7)$ & $165(63.2)$ & \\
\hline N stage, no. (\%) & & & & 0.532 \\
\hline No-1 & $64(23.2)$ & $2(13.3)$ & $62(23.8)$ & \\
\hline N2-3 & $212(76.8)$ & $13(86.7)$ & $199(76.2)$ & \\
\hline Mean tumor size $(\mathrm{cm}), \pm \mathrm{SD}$ & $3.73 \pm 1.74$ & $2.87 \pm 0.99$ & $3.76 \pm 1.76$ & 0.056 \\
\hline Brain metastasis, no. (\%) & $71(25.7)$ & $4(26.7)$ & $67(25.7)$ & 1.000 \\
\hline Liver metastasis, no. (\%) & $17(6.2)$ & $1(6.7)$ & $16(6.1)$ & 1.000 \\
\hline Bone metastasis, no. (\%) & $116(42.0)$ & $8(53.3)$ & $108(41.4)$ & 0.362 \\
\hline EGFR-TKI, no. (\%) & & & & $0.537^{c}$ \\
\hline Gefitinib & $185(67.0)$ & $9(60.0)$ & $176(67.4)$ & \\
\hline Erlotinib & $45(16.3)$ & $2(13.3)$ & $43(16.5)$ & \\
\hline Icotinib & $44(15.9)$ & $4(26.7)$ & $40(15.3)$ & \\
\hline Afatinib/Osimertinib & $2(0.8)$ & $0(0.0)$ & $2(0.8)$ & \\
\hline EGFR mutations, no. (\%) & & & & $0.362^{d}$ \\
\hline Exon 19 deletion & $117(42.4)$ & $9(60.0)$ & $108(41.4)$ & \\
\hline L858R mutation & $130(47.1)$ & $6(40.0)$ & $124(47.5)$ & \\
\hline Rare & $29(10.5)$ & $0(0.0)$ & $29(11.1)$ & \\
\hline
\end{tabular}

Abbreviations: EGFR-TKI epidermal growth factor receptor- tyrosine kinase inhibitor, ECOG PS Eastern Corporation Oncology Group performance status, SD standard deviation

${ }^{\mathrm{a} E C O G}$ PS 0 or 1 vs. 2 or 3

${ }^{\mathrm{b}}$ Recurrent/IIIB vs. Stage IV

'Gefitinib vs. Other EGFR-TKIs

${ }^{\mathrm{d} E x o n} 19$ deletion vs. others

eincluding EGFR mutations in exons 18 and 20, other than 19DEL and L858R mutations 
Table 2 Characteristics of the 15 Cavitary Adenocarcinoma patients with EGFR mutations

\begin{tabular}{|c|c|c|c|c|c|c|c|c|c|c|c|}
\hline Patient No. & Age, y & Gender & Smoking & Stage & Tumor size & Wall & EGFR mutations & EGFR-TKI & PFS, mo & Efficacy & T790 M \\
\hline 1 & 62 & Male & Never & IV & $2.6 \mathrm{~cm}$ & Thick & L858R mutation & Erlotinib & 4.7 & SD & Unknown \\
\hline 2 & 71 & Male & Never & IV & $3.6 \mathrm{~cm}$ & Thick & L858R mutation & Gefitinib & 3.3 & PR & Negative \\
\hline 3 & 52 & Female & Never & IV & $2.2 \mathrm{~cm}$ & Thick & L858R mutation & Gefitinib & 6.0 & PR & Negative \\
\hline 4 & 44 & Male & Never & IV & $2.4 \mathrm{~cm}$ & Thick & L858R mutation & Gefitinib & 9.6 & PR & Positive \\
\hline 5 & 57 & Male & Never & IV & $2.0 \mathrm{~cm}$ & Thick & L858R mutation & Gefitinib & 1.0 & PD & Negative \\
\hline 6 & 50 & Male & Smoker & IV & $2.6 \mathrm{~cm}$ & Thick & L858R mutation & Erlotinib & 4.2 & SD & Unknown \\
\hline 7 & 76 & Female & Never & IV & $5.0 \mathrm{~cm}$ & Thick & Exon 19 deletion & Gefitinib & 5.2 & SD & Unknown \\
\hline 8 & 37 & Female & Never & IV & $2.8 \mathrm{~cm}$ & Thin & Exon 19 deletion & Icotinib & 11.4 & PR & Unknown \\
\hline 9 & 75 & Male & Never & IV & $2.2 \mathrm{~cm}$ & Thin & Exon 19 deletion & Icotinib & 11.0 & $P R$ & Positive \\
\hline 10 & 61 & Female & Never & IV & $2.2 \mathrm{~cm}$ & Thin & Exon 19 deletion & Gefitinib & 24.5 & $P R$ & Positive \\
\hline 11 & 47 & Male & Smoker & IV & $4.5 \mathrm{~cm}$ & Thick & Exon 19 deletion & Gefitinib & 6.7 & $P R$ & Negative \\
\hline 12 & 48 & Male & Never & IV & $2.2 \mathrm{~cm}$ & Thick & Exon 19 deletion & Gefitinib & 6.5 & SD & Negative \\
\hline 13 & 51 & Male & Smoker & IV & $4.8 \mathrm{~cm}$ & Thin & Exon 19 deletion & Icotinib & 9.7 & SD & Negative \\
\hline 14 & 56 & Female & Never & Recurrent & $2.0 \mathrm{~cm}$ & Thin & Exon 19 deletion & Gefitinib & 4.5 & $P R$ & Positive \\
\hline 15 & 39 & Male & Smoker & IV & $2.5 \mathrm{~cm}$ & Thin & Exon 19 deletion & Icotinib & 3.0 & SD & Unknowr \\
\hline
\end{tabular}

Abbreviations: EGFR-TKI epidermal growth factor receptor- tyrosine kinase inhibitor, ECOG PS Eastern Corporation Oncology Group performance status, SD standard deviation, $P R$ partial response, $S D$ stable disease, $P D$ progressive disease, $P F S$ median progression-free survival

level was set at $P<0.05$. Data were analyzed using the Statistical Package for the Social Sciences Version 23.0 Software (SPSS, Inc., Chicago, IL) and the survival curve was drawn with GraphPad Prism 5.01 (GraphPad Software, San Diego, CA).

\section{Results}

\section{Patient characteristics}

Two hundred and seventy-six patients were evaluated for the present study. Cavitary ADC was identified in 5.4\% (15/276) of patients with EGFR-mutant lung ADC. The median age of cavitary ADC was 61 years (range, 37 to 76). Specifically, cavitary ADC was more common in male patients when compared with noncavitary ADC (66.7\% vs. $33.0 \%, P=0.008)$. The tumor size of cavitary ADC was marginally smaller than that of noncavitary ADC (2.87 vs. $3.76 \mathrm{~cm}, P=0.056$ ). As shown in Table 1 , there was no significant difference between cavitary and noncavitary ADC in terms of smoking history, ECOG PS, TNM stage, the incidence of brain, liver and bone metastases, types of EGFR mutations, and types of EGFR-TKIs received.

\section{Characteristics of the cavitary ADC patients with EGFR mutations}

Of the 15 cavitary ADC patients with EGFR mutations, 10 were male and 5 were female, 11 were never-smokers
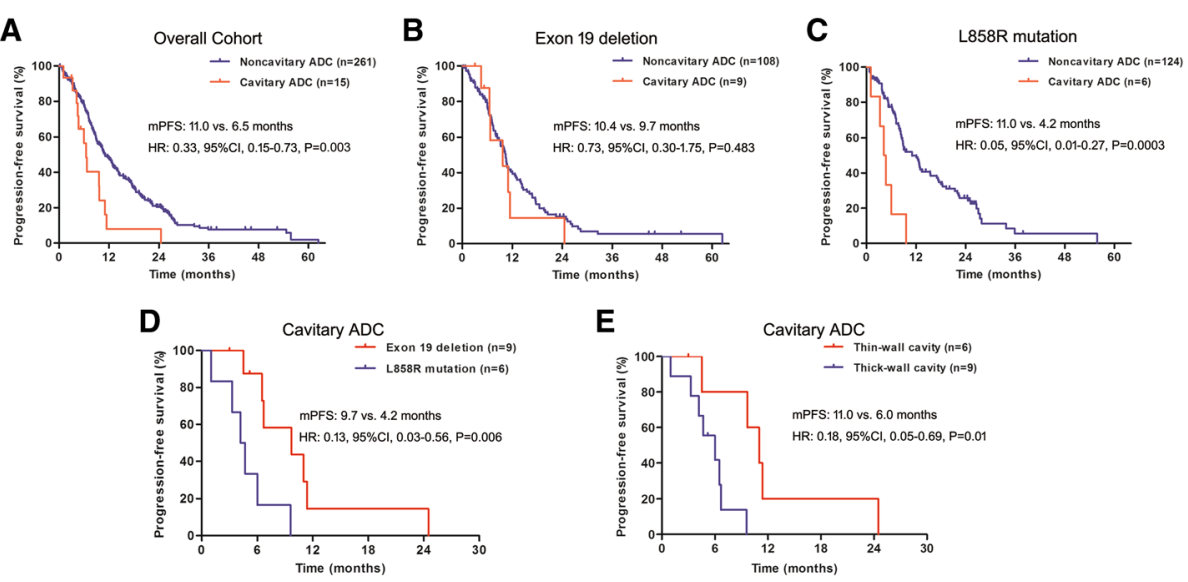

Fig. 1 Progression-free survival of first-line EGFR-TKIs in lung adenocarcinoma patients harboring EGFR sensitizing mutations. a overall cohort; b in patients with Exon 19 deletion; $\mathbf{c}$ in patients with L858R mutation; $\mathbf{d}$ in patients with cavitary adenocarcinoma according to mutational status; e in patients with cavitary adenocarcinoma according to the thickness of cavity wall. Abbreviations: EGFR-TKI, epidermal growth factor receptor- tyrosine kinase inhibitor 
Table 3 A Brief Summary of Responses to EGFR-TKI Treatment in cavitary and noncavitary adenocarcinoma patients with EGFR mutations

\begin{tabular}{llll}
\hline Characteristic & $\begin{array}{l}\text { Cavity } \\
N=15\end{array}$ & $\begin{array}{l}\text { Noncavity } \\
N=261\end{array}$ & $P$ \\
\hline Response, no. (\%) & & & \\
CR & $0(0.0)$ & $0(0.0)$ & \\
PR & $8(53.3)$ & $154(59.0)$ & \\
SD & $6(40.0)$ & $86(33.0)$ & \\
PD & $1(6.7)$ & $21(8.0)$ & \\
mPFS (95\%Cl), mo & & & 0.006 \\
Overall cohort & $6.5(5.3-7.7)$ & $11.0(9.3-12.7)$ & 0.483 \\
Exon 19 deletion & $9.7(2.1-17.3)$ & $10.4(9.0-11.8)$ & $<0.001$ \\
L858R mutation & $4.2(2.5-5.9)$ & $11.0(7.6-14.4)$ & \\
ORR, \% & & & 0.664 \\
Overall cohort & 53.3 & 59.0 & 0.737 \\
Exon 19 deletion & 55.6 & 61.1 & 1.000 \\
L858R mutation & 50.0 & 54.8 & 1.000 \\
DCR, \% & & & 1.000 \\
Overall cohort & 93.3 & 92.0 & 0.387 \\
Exon 19 deletion & 100.0 & 90.7 & \\
L858R mutation & 83.3 & 92.7 & \\
\hline
\end{tabular}

Abbreviations: EGFR-TKI epidermal growth factor receptor- tyrosine kinase inhibitor, $C R$ complete response, $P R$ partial response, $S D$ stable disease, $P D$ progressive disease, $m P F S$ median progression-free survival, ORR objective response rate, $D C R$ disease control rate

and 4 were former or current smokers. Fourteen patients had stage IV disease and 1 had recurrent disease. Regarding mutational status, 9 patients had 19DEL and 6 harbored L858R mutation. All patients received firstgeneration EGFR-TKI as initial treatment, including 9 who received gefitinib, 2 who received erlotinib, and 4 who received icotinib. Regarding wall thickness of the cavity, 9 patients had thick-wall cavity while 6 had thin-wall cavity. When acquired resistance develops, 10 patients provided tumor tissue for evaluating the mechanisms of acquired resistance. The proportion of T790 M mutation was $40 \%(4 / 10)$ in overall group, $25 \%(1 / 4)$ in L858R mutation group, and 50\% (3/6) in 19DEL group. The detailed characteristics of the cavitary ADC patients with EGFR mutations are listed in Table 2.

\section{Therapeutic responses to EGFR-TKI treatment in cavitary and noncavitary ADC patients with EGFR mutations}

The median PFS in patients with noncavitary ADC was significantly better than those with cavitary ADC (11.0 versus 6.5 months, hazard ratio [HR]: 0.33, 95\% confidence interval $[\mathrm{CI}], 0.15-0.73, P=0.003$ ) (Fig. 1a). The ORR for patients who had noncavitary ADC versus those who had cavitary ADC was $59.0 \%$ versus $53.3 \%$, respectively $(P=0.664)$, and the disease control rate (DCR) was $93.3 \%$ versus $92.0 \%$, respectively $(P=1.000)$.

We further evaluated the efficacy of EGFR-TKIs in cavitary and noncavitary ADC according to mutational status (19DEL vs. L858R mutation). Interestingly, noncavitary ADC had significantly better PFS than cavitary ADC in patients with L858R mutation (11.0 vs. 4.2 months, HR: $0.05,95 \% \mathrm{CI}, 0.01-0.27, P=0.0003$ ) while the PFS was not significantly different in patients with 19DEL (10.4 versus 9.7 months, HR: 0.73 , 95\%CI, $0.30-1.75, P=0.483$ ) (Fig. $1 \mathrm{~b}-\mathrm{c})$. The ORR (50.0\% versus $54.8 \%, P=1.000)$ and $\operatorname{DCR}(83.3 \%$ versus $92.7 \%, P=$ 0.387 ) were numerically lower in cavitary ADC when compared with noncavitary ADC in patients with L858R mutation. Furthermore, cavitary ADC patient with 19DEL had better PFS than those with L858R mutation (9.7 versus 4.2 months, HR: $0.13,95 \% \mathrm{CI}, 0.03-0.56, P=$ 0.006) (Fig. 1d). When cavitary ADC was classified according to wall thickness of the cavity, patients with thin-wall cavity had longer PFS (11.0 versus 6.0 months, HR: $0.18,95 \% C I, 0.05-0.69, P=0.01$ ) (Fig. 1e), higher ORR (66.7\% versus $44.4 \%, P=0.608)$ and DCR $(100.0 \%$ versus $88.9 \%, P=1.000)$ than those with thick-wall cavity. The therapeutic responses to EGFR-TKI treatment in cavitary and noncavitary ADC patients with EGFR mutations are summarized in Tables 2 and 3. Furthermore, two representative cases showed that noncavitary ADC had higher tumor permeability, BF, BV and MTT than cavitary ADC (Fig. 2a-b).

\section{Univariate and multivariate analysis on PFS}

Univariate analysis identified noncavitary ADC and tumor size $\leq 5 \mathrm{~cm}$ as being significantly associated with better PFS. Multivariate analysis revealed cavity as an independent predictive factor for PFS (HR: 0.49, 95\% CI, $0.26-0.90, P=0.022$ ), as well as age (HR: $0.69,95 \% \mathrm{CI}$, $0.49-0.98, P=0.036)$ and tumor size (HR: $1.74,95 \% \mathrm{CI}$, 1.16-2.62, $P=0.008$ ) (Table 4).

\section{Discussion}

To our knowledge, the current study is the first to investigate the incidence and clinical characteristics of EGFR-mutant cavitary ADC and its impact on the therapeutic response to first-line EGFR-TKI therapy. Similar with previous study conducted in overall lung ADC population [14], cavity occurred in $5.4 \%$ of patients with EGFR-mutant lung ADC and was more prevalent among male patients. Interestingly, our study showed that cavity formation had an adverse impact on the PFS of EGFR-mutant ADC treated with first-line EGFR-TKIs. Furthermore, the impaired effect was only observed in patients with L858R mutation but not in those with 19DEL.

Recent evidence suggested patients with 19DEL and L858R mutation may be two distinct subtypes and have 

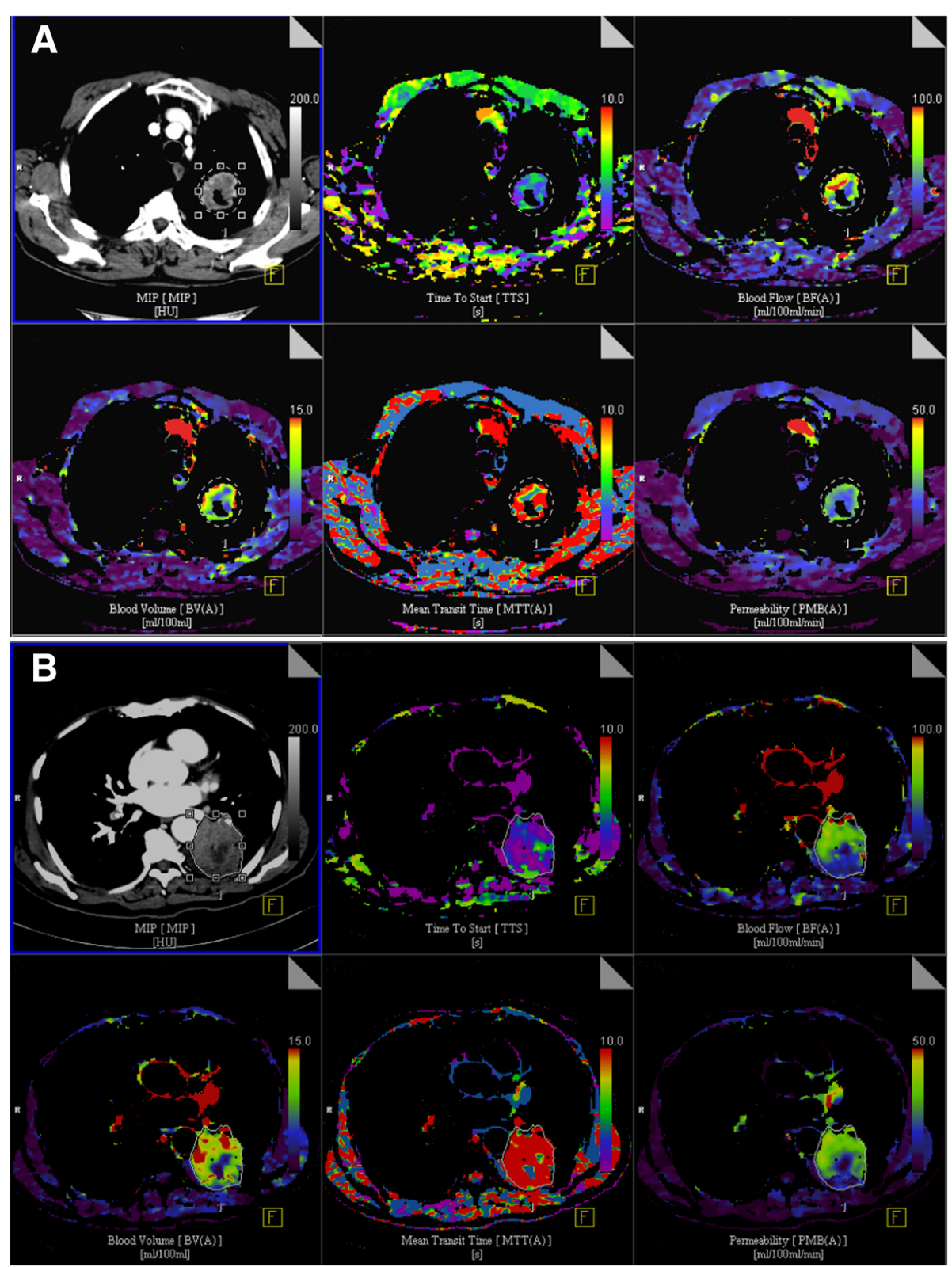

Fig. 2 The dVPCT indirectly demonstrated thick-wall cavitary ADC were more hypoxic than non-cavitary ADC. The tumor permeability, blood flow, blood volume and mean transit time was higher in patients with a non-cavitary ADC than $\mathbf{b}$ thick-wall cavitary ADC. Abbreviations: dVPCT, the dynamic volume perfusion CT

different survival outcomes [25]. To date, the possible mechanism remains unclear. In this small fraction of patients, namely EGFR-mutant cavitary ADC in our study, we also observed a significantly different PFS among patients with these two subtypes of EGFR mutations treated with first-line EGFR-TKIs (19DEL versus L858R: 9.7 and 4.2 months, $P=0.006$ ). In the present study, we noticed that all six cavitary ADC patients with L858R mutation had thick-wall cavity (greater than $4 \mathrm{~mm}$ ) while thick-wall cavity was only identified in one thirds (3/9) of patients with 19DEL. Further analyses showed that patients with thick-wall cavity had worse PFS (6.0 versus 11.0 months, $P=0.01)$ and ORR $(44.4 \%$ versus $66.7 \%, P=0.608)$ than those with thin-wall cavity, suggesting thick-wall cavity may be the main cause that contribute to the worse PFS of first-line EGFR-TKIs in patients with L858R-mutant cavitary ADC. Watanabe et al. previously demonstrated that thick-wall cavitary ADC had poorer survival and a higher frequency of solid predominant tumors, vascular invasion and bronchiolar obstruction than those with thin-wall cavity [18]. Because of the high probability of feeding vessel invasion and 
Table 4 Univariate and Multivariate Cox regression analyses for PFS in Cavitary and Noncavitary Adenocarcinoma patients with EGFR mutations

\begin{tabular}{|c|c|c|c|c|}
\hline \multirow[t]{2}{*}{ Variables } & \multicolumn{2}{|l|}{ Univariate Analysis } & \multicolumn{2}{|l|}{ Multivariate Analysis } \\
\hline & $\mathrm{HR}(95 \% \mathrm{Cl})$ & $P$ & HR $(95 \% \mathrm{Cl})$ & $P$ \\
\hline Noncavity vs. Cavity & $0.478(0.271-0.843)$ & 0.011 & $0.485(0.261-0.902)$ & 0.022 \\
\hline Female vs. Male & $0.846(0.635-1.127)$ & 0.252 & $0.793(0.528-1.190)$ & 0.263 \\
\hline Age $>65$ y vs. $\leq 65 y$ & $0.790(0.587-1.062)$ & 0.118 & $0.691(0.489-0.976)$ & 0.036 \\
\hline ECOG PS > 1 vs. 0 or 1 & $0.841(0.651-1.086)$ & 0.183 & $0.921(0.674-1.259)$ & 0.605 \\
\hline Smokers vs. non-smokers & $1.124(0.794-1.591)$ & 0.511 & $0.919(0.571-1.480)$ & 0.728 \\
\hline TNM Stage IV vs. stage III + Recurrent & $1.022(0.901-1.160)$ & 0.731 & $0.972(0.842-1.122)$ & 0.698 \\
\hline Other EGFR-TKIs ${ }^{a}$ vs. Gefitinib & $0.898(0.666-1.212)$ & 0.483 & $0.806(0.574-1.132)$ & 0.214 \\
\hline Tumor size: $>5 \mathrm{~cm}$ vs. $\leq 5 \mathrm{~cm}$ & $1.886(1.282-2.775)$ & 0.001 & $1.741(1.158-2.619)$ & 0.008 \\
\hline \multicolumn{5}{|l|}{ EGFR mutation } \\
\hline Exon 19 deletion & 1.000 (reference) & & 1.000 (reference) & \\
\hline L858R mutation & $1.564(0.988-2.477)$ & 0.056 & $1.133(0.659-1.949)$ & 0.651 \\
\hline Rare mutations ${ }^{\mathrm{b}}$ & $1.339(0.843-2.127)$ & 0.217 & $1.140(0.674-1.928)$ & 0.626 \\
\hline
\end{tabular}

bronchiolar obstruction, thick-wall cavity was more likely to result in a hypoxia microenvironment, therefore leading to resistance to EGFR-TKIs. The dVPCT also indirectly demonstrated thick-wall cavitary ADC were more hypoxic, as microvessel density was positively associated with BF and BV and lower BV indicated a more hypoxia status [26, 27]. A previous study also found that patients with solid predominant subtype of ADC harboring EGFR mutations had significantly lower ORR (61\% versus $88 \%, P=0.03)$, shorter PFS (7.7 versus 13.5 months, $P=0.002)$ and $\mathrm{OS}(21.5$ versus 31.0 months, $P=0.028)$ than those with non-solid predominant subtype of ADC [28]. Therefore, the high frequency of solid predominant subtype in thick-wall cavitary ADC may also relate to the poor therapeutic response to EGFR-TKIs in L858R-mutant cavitary ADC. A previous study found that L858R mutation can increase cancer cell invasive ability and malignant pleural effusion formation through activation of the CXCL12-CXCR4 pathway [29]. However, why L858Rmutant ADC tends to promote thick-wall cavity formation needs further investigation.

Another important factor that contribute to the better survival of cavitary ADC patients with 19DEL may be the higher proportion of the T790 M mutation after acquired resistance [30]. In the recent study by Ke et al., they found that patients with 19DEL were more likely to have T790 M mutation than those with L858R mutation when acquired resistance develops $(50.4 \%$ versus $36.5 \%, P=$ 0.043) [30]. The median overall survival of patients with T790 M mutation was 36.0 months, which was better than those with other acquired resistance mechanisms, including MET-amplification, histology-transformation and
KRAS/PIK3CA/ALK alterations [30]. In our study, when acquired resistance develops, 25\% (1/4) patients with L858R mutation had T790 M mutation while 50\% (3/6) in patients with 19DEL. Although the analyzed cases in our study were very small, the incidence of T790 M mutation was in line with previous findings [30-32].

Our study has several strengths including: (1) all patients were newly diagnosed ADC treated with first-line EGFR-TKIs, which ruled out any impact on patients' outcomes by possible disproportionate pretreatment; (2) all enrolled patients received high-resolution thin-section CT scans $(1 \mathrm{~mm})$ in our hospital so that we can accurately evaluate the incidence and characteristics of cavitary ADC. However, our study was also limited in several aspects: (1) it was affected by the limitations inherent to studies with a retrospective design; (2) most of the enrolled patients were diagnosed based on small specimens and ADC subtyping based on small samples is challenging [33-35], so we cannot evaluate whether solid predominant subtype was indeed associated with thick-wall cavity that result in a worse PFS in L858R-mutant cavitary ADC; (3) despite the overall population was large, the number of EGFR-mutant cavitary ADC was small, therefore, a large sample study is needed to validate these findings.

\section{Conclusions}

Cavity occurred in $5.4 \%$ of patients with EGFR-mutant ADC and was associated with a worse PFS of first-line EGFR-TKI therapy, mainly in those with L858R mutation. Thick-wall cavity formation may be the main cause that contribute to the worse PFS of patients with L858R-mutant cavitary ADC. 


\section{Abbreviations}

19DEL: Exon 19 deletion; 95\%Cl: 95\% confidence interval; ADC: Adenocarcinoma; ALK: Anaplastic Lymphoma Kinase.; ARMS: Amplification refractory mutation system; BF: Blood flow; BV: Blood volume; CT: Computed tomography; DCR: Disease control rate; dVPCT: Dynamic volume perfusion CT; EGFRTKIs: Epidermal growth factor receptor-tyrosine kinase inhibitors; HR: Hazard ratio; KRAS: Kirsten rat sarcoma viral oncogene homolog; L858R: Leu858Arg point mutation in exon 21; MET: Mesenchymal-epithelial-transformation; MTT: Mean transit time; ORR: Objective response rate; PFS: Progression-free survival; PIK3CA: Phosphatidylinositol-4,5-bisphosphate 3-kinase catalytic subunit alpha; QoL: Quality of life; WHO: World Health Organization

\section{Funding}

This study was partially supported by Shanghai Sailing Program (16YF1409600), and the National Natural Science Foundation of China (81703020), Shanghai Committee of Science and technology (No. 14411970800), and Shanghai Municipal Commission of Health and Family Planning (No.20144Y0190)

\section{Availability of data and materials}

The datasets used and analyzed during the current study are available from the corresponding author on reasonable request.

\section{Authors' contributions}

Conceived and designed the experiments: FZ, WM and JS. Data collection: All authors. Analyzed the data: FZ, WM, WL, and JZ. Wrote the paper: FZ, WM, WL, and XC. Approval of the paper: All authors.

\section{Ethics approval and consent to participate}

The study protocol was approved by the Ethics Committee of Shangha Pulmonary Hospital. The written informed consent was obtained from each participant to use the clinical data for research before any medical interventions.

\section{Consent for publication}

Not applicable

\section{Competing interests}

The authors declare that they have no competing interests.

\section{Publisher's Note}

Springer Nature remains neutral with regard to jurisdictional claims in published maps and institutional affiliations.

\section{Author details}

'Department of Oncology, Shanghai Pulmonary Hospital, Tongji University School of Medicine, No 507 Zhengmin Road, Yangpu District, Shanghai, China. ${ }^{2}$ Department of Intensive Care Unit, Shanghai Jingan District Shibei Hospital, Shanghai, China. ${ }^{3}$ Department of Imaging, Shanghai Pulmonary Hospital, Tongji University School of Medicine, No 507 Zhengmin Road, Yangpu District, Shanghai 200433, China.

\section{Received: 1 August 2018 Accepted: 11 October 2018}

\section{Published online: 23 October 2018}

\section{References}

1. Sun Y, Ren Y, Fang Z, Li C, Fang R, Gao B, Han X, Tian W, Pao W, Chen H, et al. Lung adenocarcinoma from east Asian never-smokers is a disease largely defined by targetable oncogenic mutant kinases. J Clin Oncol. 2010;28(30):4616-20.

2. Ren S, Chen X, Kuang P, Zheng L, Su C, Li J, Li B, Wang Y, Liu L, Hu Q, et al. Association of EGFR mutation or ALK rearrangement with expression of DNA repair and synthesis genes in never-smoker women with pulmonary adenocarcinoma. Cancer. 2012;118(22):5588-94.

3. Li H, Pan Y, Li Y, Li C, Wang R, Hu H, Zhang Y, Ye T, Wang L, Shen L, et al. Frequency of well-identified oncogenic driver mutations in lung adenocarcinoma of smokers varies with histological subtypes and graduated smoking dose. Lung Cancer. 2013;79(1):8-13.

4. An SJ, Chen ZH, Su J, Zhang XC, Zhong WZ, Yang JJ, Zhou Q, Yang XN, Huang $L$, Guan $J L$, et al. Identification of enriched driver gene alterations in subgroups of non-small cell lung cancer patients based on histology and smoking status. PLoS One. 2012;7(6):e40109.
5. Mok TS, Wu YL, Thongprasert S, Yang CH, Chu DT, Saijo N, Sunpaweravong $P$, Han B, Margono B, Ichinose $Y$, et al. Gefitinib or carboplatin-paclitaxel in pulmonary adenocarcinoma. N Engl J Med. 2009;361(10):947-57.

6. Zhou C, Wu YL, Chen G, Feng J, Liu XQ, Wang C, Zhang S, Wang J, Zhou S, Ren $\mathrm{S}$, et al. Erlotinib versus chemotherapy as first-line treatment for patients with advanced EGFR mutation-positive non-small-cell lung cancer (OPTIMAL, CTONG-0802): a multicentre, open-label, randomised, phase 3 study. Lancet Oncol. 2011;12(8):735-42.

7. Wu YL, Zhou C, Hu CP, Feng J, Lu S, Huang Y, Li W, Hou M, Shi JH, Lee KY, et al. Afatinib versus cisplatin plus gemcitabine for first-line treatment of Asian patients with advanced non-small-cell lung cancer harbouring EGFR mutations (LUX-lung 6): an open-label, randomised phase 3 trial. Lancet Oncol. 2014;15(2):213-22.

8. Rosell R, Carcereny E, Gervais R, Vergnenegre A, Massuti B, Felip E, Palmero R, Garcia-Gomez R, Pallares C, Sanchez JM, et al. Erlotinib versus standard chemotherapy as first-line treatment for European patients with advanced EGFR mutation-positive non-small-cell lung cancer (EURTAC): a multicentre, open-label, randomised phase 3 trial. Lancet Oncol. 2012;13(3):239-46.

9. Gasinska A, Kolodziejski L, Niemiec J, Dyczek S. Clinical significance of biological differences between cavitated and solid form of squamous cell lung cancer. Lung Cancer. 2005;49(2):171-9.

10. Kolodziejski LS, Dyczek S, Duda K, Goralczyk J, Wysocki WM, Lobaziewicz W. Cavitated tumor as a clinical subentity in squamous cell lung cancer patients. Neoplasma. 2003;50(1):66-73.

11. Chaudhuri MR. Primary pulmonary cavitating carcinomas. Thorax. 1973; 28(3):354-66.

12. Mouroux J, Padovani B, Elkaim D, Richelme H. Should cavitated bronchopulmonary cancers be considered a separate entity? Ann Thorac Surg. 1996;61(2):530-2.

13. Miura $\mathrm{H}$, Taira $\mathrm{O}$, Hiraguri $\mathrm{S}$, Hagiwara $\mathrm{M}$, Kato $\mathrm{H}$. Cavitating adenocarcinoma of the lung. Ann Thorac Cardiovasc Surg. 1998;4(3):154-8.

14. Watanabe Y, Kusumoto M, Yoshida A, Suzuki K, Asamura H, Tsuta K. Surgically resected solitary cavitary lung adenocarcinoma: association between clinical, pathologic, and radiologic findings and prognosis. Ann Thorac Surg. 2015;99(3):968-74.

15. Murakami A, Takahashi F, Nurwidya F, Kobayashi I, Minakata K, Hashimoto M, Nara T, Kato M, Tajima K, Shimada N, et al. Hypoxia increases gefitinibresistant lung cancer stem cells through the activation of insulin-like growth factor 1 receptor. PLoS One. 2014;9(1):e86459.

16. Minakata K, Takahashi F, Nara T, Hashimoto M, Tajima K, Murakami A, Nurwidya F, Yae S, Koizumi F, Moriyama H, et al. Hypoxia induces gefitinib resistance in non-small-cell lung cancer with both mutant and wild-type epidermal growth factor receptors. Cancer Sci. 2012;103(11):1946-54.

17. Travis WD, Brambilla E, Noguchi M, Nicholson AG, Geisinger KR, Yatabe $Y$, Beer DG, Powell CA, Riely GJ, Van Schil PE, et al. International association for the study of lung cancer/american thoracic society/european respiratory society international multidisciplinary classification of lung adenocarcinoma. J Thorac Oncol. 2011;6(2):244-85.

18. Watanabe Y, Kusumoto M, Yoshida A, Shiraishi K, Suzuki K, Watanabe SI, Tsuta K. Cavity Wall thickness in solitary Cavitary lung adenocarcinomas is a prognostic indicator. Ann Thorac Surg. 2016;102(6):1863-71.

19. Shi J, Schmid-Bindert G, Fink C, Sudarski S, Apfaltrer P, Pilz LR, Liu B, Haberland U, Klotz E, Zhou C, et al. Dynamic volume perfusion $C T$ in patients with lung cancer: baseline perfusion characteristics of different histological subtypes. Eur J Radiol. 2013;82(12):e894-900.

20. Sudarski S, Shi J, Schmid-Bindert G, Manegold C, Pilz LR, Zhou C, Schoenberg SO, Henzler T. Dynamic volume perfusion computed tomography parameters versus RECIST for the prediction of outcome in lung cancer patients treated with conventional chemotherapy. J Thorac Oncol. 2015:10(1):164-71.

21. Zhao M, Zhang Y, Cai W, Li J, Zhou F, Cheng N, Ren R, Zhao C, Li X, Ren S, et al. The Bim deletion polymorphism clinical profile and its relation with tyrosine kinase inhibitor resistance in Chinese patients with non-small cell lung cancer. Cancer. 2014;120(15):2299-307.

22. Li W, Ren S, Li J, Li A, Fan L, Li X, Zhao C, He Y, Gao G, Chen X, et al. T790M mutation is associated with better efficacy of treatment beyond progression with EGFR-TKI in advanced NSCLC patients. Lung Cancer. 2014;84(3):295-300.

23. Ding T, Zhou F, Chen X, Zhang S, Liu Y, Sun H, Ren S, Li X, Zhao C, Wang H, et al. Continuation of gefitinib plus chemotherapy prolongs progressionfree survival in advanced non-small cell lung cancer patients who get acquired resistance to gefitinib without T790M mutations. J Thorac Dis. 2017;9(9):2923-34 
24. Zhou F, Hou L, Ding T, Song Q, Chen X, Su C, Li W, Gao G, Ren S, Wu F, et al. Distinct clinicopathologic features, genomic characteristics and survival of central and peripheral pulmonary large cell neuroendocrine carcinoma: from different origin cells? Lung Cancer. 2018;116:30-7.

25. Lee CK, Wu YL, Ding PN, Lord SJ, Inoue A, Zhou C, Mitsudomi T, Rosell R, Pavlakis N, Links M, et al. Impact of specific epidermal growth factor receptor (EGFR) mutations and clinical characteristics on outcomes after treatment with EGFR tyrosine kinase inhibitors versus chemotherapy in EGFR-mutant lung Cancer: a meta-analysis. J Clin Oncol. 2015;33(17):1958-65.

26. Spira D, Neumeister H, Spira SM, Hetzel J, Spengler W, von Weyhern CH, Horger M. Assessment of tumor vascularity in lung cancer using volume perfusion CT (VPCT) with histopathologic comparison: a further step toward an individualized tumor characterization. J Comput Assist Tomogr. 2013; 37(1):15-21.

27. Mandeville HC, Ng QS, Daley FM, Barber PR, Pierce G, Finch J, Burke M, Bell $A$, Townsend ER, Kozarski R, et al. Operable non-small cell lung cancer: correlation of volumetric helical dynamic contrast-enhanced CT parameters with immunohistochemical markers of tumor hypoxia. Radiology. 2012; 264(2):581-9.

28. Yoshida T, Ishii G, Goto K, Yoh K, Niho S, Umemura S, Matsumoto S, Ohmatsu $H$, Nagai $K$, Ohe Y, et al. Solid predominant histology predicts EGFR tyrosine kinase inhibitor response in patients with EGFR mutation-positive lung adenocarcinoma. J Cancer Res Clin Oncol. 2013;139(10):1691-700.

29. Tsai MF, Chang TH, Wu SG, Yang HY, Hsu YC, Yang PC, Shih JY. EGFR-L858R mutant enhances lung adenocarcinoma cell invasive ability and promotes malignant pleural effusion formation through activation of the CXCL12CXCR4 pathway. Sci Rep. 2015:5:13574.

30. Ke EE, Zhou Q, Zhang QY, Su J, Chen ZH, Zhang XC, Xu CR, Yang JJ, Tu HY, Yan HH, et al. A higher proportion of the EGFR T790M mutation may contribute to the better survival of patients with exon 19 deletions compared with those with L858R. J Thorac Oncol. 2017;12(9):1368-75.

31. Sun JM, Ahn MJ, Choi YL, Ahn JS, Park K. Clinical implications of T790M mutation in patients with acquired resistance to EGFR tyrosine kinase inhibitors. Lung Cancer. 2013;82(2):294-8.

32. Hata A, Katakami N, Yoshioka H, Takeshita J, Tanaka K, Nanjo S, Fujita S, Kaj $\mathrm{R}$, Imai $\mathrm{Y}$, Monden $\mathrm{K}$, et al. Rebiopsy of non-small cell lung cancer patients with acquired resistance to epidermal growth factor receptor-tyrosine kinase inhibitor: comparison between T790M mutation-positive and mutation-negative populations. Cancer. 2013;119(24):4325-32.

33. Rodriguez EF, Monaco SE, Dacic S. Cytologic subtyping of lung adenocarcinoma by using the proposed International Association for the Study of Lung Cancer/American Thoracic Society/European Respiratory Society (IASLC/ATS/ERS) adenocarcinoma classification. Cancer Cytopathol. 2013;121(11):629-37.

34. Matsuzawa R, Kirita K, Kuwata T, Umemura S, Matsumoto S, Fujii S, Yoh K, Kojima M, Niho S, Ohmatsu H, et al. Factors influencing the concordance of histological subtype diagnosis from biopsy and resected specimens of lung adenocarcinoma. Lung Cancer. 2016:94:1-6.

35. Huang KY, Ko PZ, Yao CW, Hsu CN, Fang HY, Tu CY, Chen HJ. Inaccuracy of lung adenocarcinoma subtyping using preoperative biopsy specimens. J Thorac Cardiovasc Surg. 2017;154(1):332-9 e331.

Ready to submit your research? Choose BMC and benefit from:

- fast, convenient online submission

- thorough peer review by experienced researchers in your field

- rapid publication on acceptance

- support for research data, including large and complex data types

- gold Open Access which fosters wider collaboration and increased citations

- maximum visibility for your research: over $100 \mathrm{M}$ website views per year

At BMC, research is always in progress.

Learn more biomedcentral.com/submissions 